\title{
Challenges of Management of Arteriovenous Malformation of the Pinna in a Low Resource Setting: A Case Report
}

\section{Adekunle Kazeem Adeagbo', Adekunle Daniel2 ${ }^{2}$, Segun Ayodeji Ogunkeyede², Olukayode Ayodele Iyun ${ }^{3}$}

${ }^{1}$ Department of Otorhinolaryngology, University College Hospital, Ibadan, Nigeria

${ }^{2}$ Department of Otorhinolaryngology, College of Medicine, University of Ibadan, Ibadan and University College Hospital, Ibadan, Nigeria

${ }^{3}$ Department of Plastic, Reconstructive and Aesthetic Surgery, University College Hospital, Ibadan, Nigeria

Email:dkunle2013@yahoo.co.uk

How to cite this paper: Adeagbo, A.K., Daniel, A., Ogunkeyede, S.A. and Iyun, O.A. (2020) Challenges of Management of Arteriovenous Malformation of the Pinna in a Low Resource Setting: A Case Report. Case Reports in Clinical Medicine, 9, 255-262. https://doi.org/10.4236/crcm.2020.98036

Received: July 14, 2020

Accepted: August 24, 2020

Published: August 27, 2020

Copyright $\odot 2020$ by author(s) and Scientific Research Publishing Inc. This work is licensed under the Creative Commons Attribution International License (CC BY 4.0).

http://creativecommons.org/licenses/by/4.0/

\begin{abstract}
Arteriovenous Malformation (AVM) is a lesion of vascular development characterized by an abnormal communication between an artery and a vein without an intervening capillary bed. AVM of the pinna is very rare with very few reported cases in Africa. Management of an AVM is often daunting, most especially in a resource challenged centre like ours where facilities for super selective embolization are not available. We present the case of a 17-year-old female with a pulsatile swelling of the left pinna since childhood. Clinical and radiological diagnosis of arteriovenous malformation was made. She was managed surgically with left external carotid artery ligation, partial auricular resection and postauricular scalp rotation flap cover of the cartilage remnant. The aetiopathogenesis, clinical presentation, diagnostic confirmation and treatment options are discussed. We also discuss the challenges of managing AVM in poor resource settings like ours.
\end{abstract}

\section{Keywords}

Arteriovenous Malformation, Pinna, Auriculectomy, External Carotid Artery Ligation

\section{Introduction}

Arteriovenous Malformations (AVMs) are lesions of abnormal vascular development characterized by an abnormal communication between one or more arteries and veins without an intervening capillary bed [1]. Arteriovenous malfor- 
mations are rare in the head and neck and when they do occur, usually arise from intracranial vessels. Spontaneous involvement of the pinna is a rare clinical entity whose management poses a great challenge to the surgeon. The highest level of research on this subject is a few case series and case reports [2] [3] [4]. As such recommendations on management are based on experiences of surgeons who have managed these cases at one point or the other [5] [6]. We present a 17-year-old female who had both clinical and radiological diagnosis of a Schobinger stage III AVM of the left pinna and was managed surgically with no recurrence at one year follow up. This case report, after obtaining the assent of the patient and full consent of her parents, becomes imperative considering the peculiarities of a resource challenged setting. We also discuss the clinical presentation, investigations and surgical treatment of AVM of the pinna.

\section{Case Report}

A 17-year-old female presented to our clinic with a history of a diffuse swelling of the left pinna since childhood. The swelling was painless and its growth was very slow, involving only the helix until she was about 13 years of age when the growth became rapid as well as extending to involve the rest of the pinna sparing the tragus and the lobule. Erstwhile, she had been managed as a case of auricular haemangioma at the referring hospital. The swelling was pulsatile and had begun to bleed spontaneously. The last episode of bleeding was 2 months prior to presentation and was life threatening necessitating blood transfusion.

Examination showed an obvious asymmetry of the pinna. The left pinna was swollen and felt spongy. There was a healing ulcer (site of previous bleed) at the region of the helix and scaphoid fossa. The pinna was pulsatile with a palpable thrill and audible bruit. The external auditory canal, tympanic membrane, facial nerve examination and tuning fork examination were all normal. A clinical diagnosis of AVM was made (Figure 1).
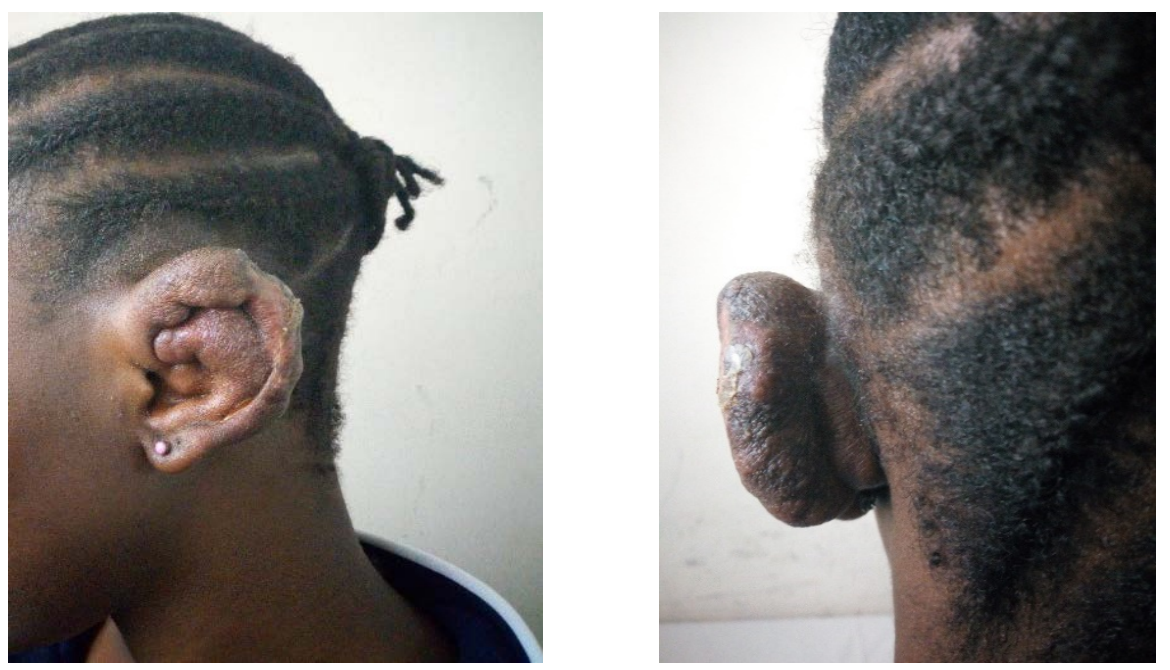

Figure 1. Left Arteriovenous malformation involving the entire pinna and sparing the lobule. 
The patient subsequently had a Magnetic Resonance Imaging (MRI) and Magnetic Resonance Angiography (MRA) of the left temporal region to define the extent of the lesion and the vessels involved. The MRI showed extensive areas of mixed intensity lesions involving the left pinna and the adjoining periauricular region (Figure 2).

The MRA showed irregular serpinginous vessels which were branches of the left superficial temporary artery (STA). There was involvement of the left maxillary artery within the nidus of entangled vessels. There were also dilated veins returning blood from the AVM (Figure 3).
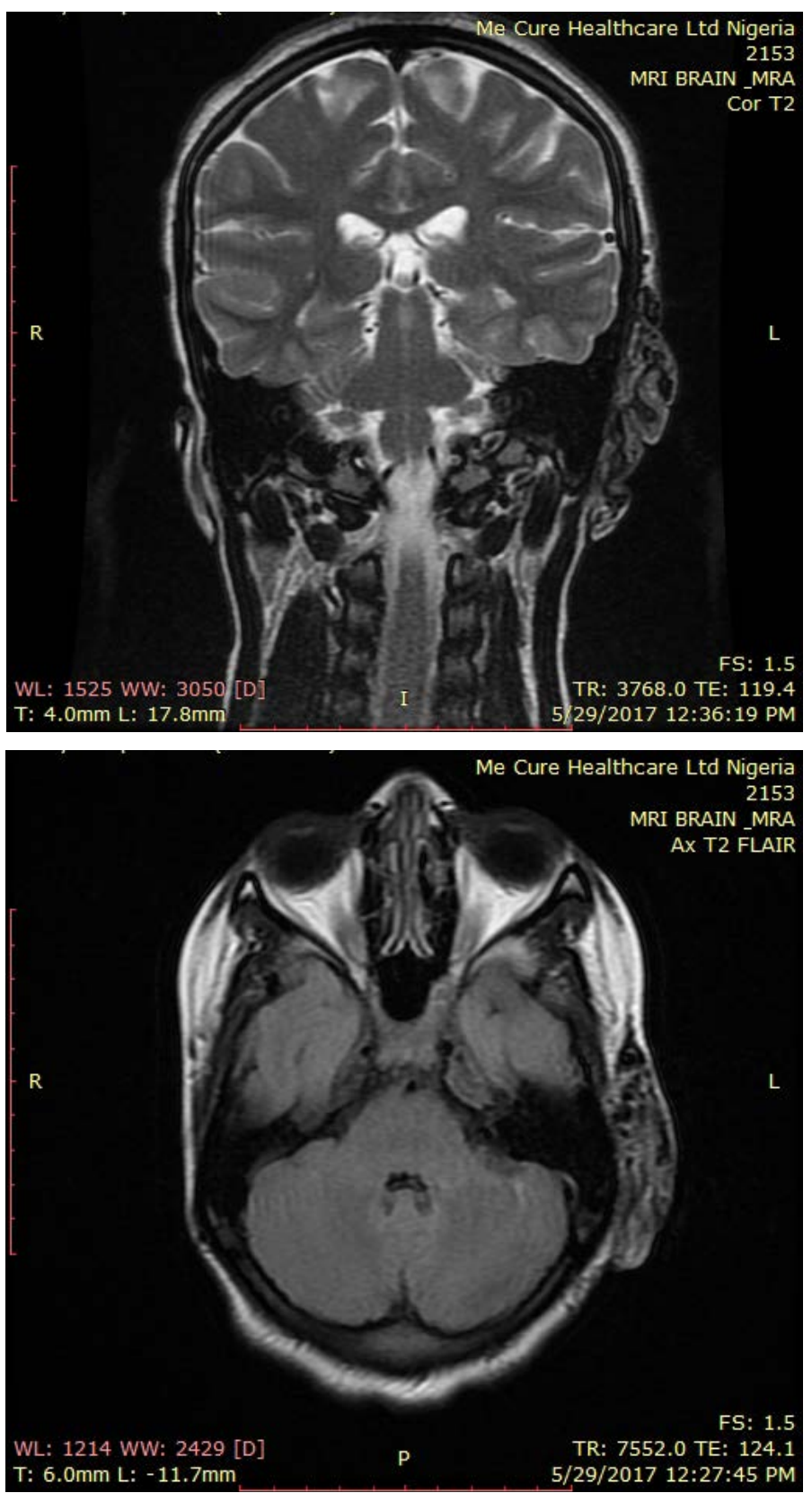

Figure 2. Magnetic Resonance Imaging showing areas affected areas of the temporal region. 

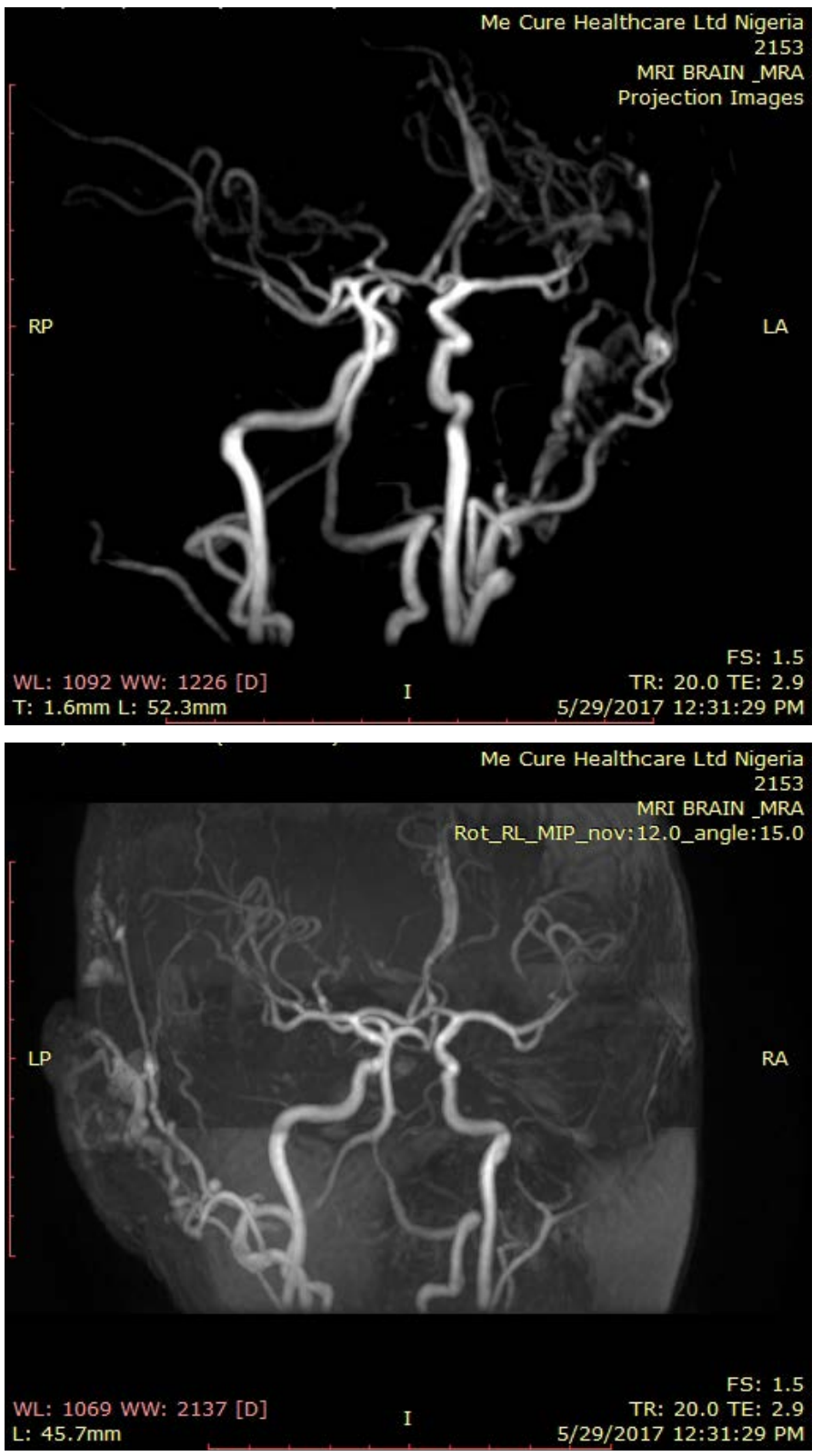

Figure 3. Magnetic Resonance Angiography showing the vessels involved in the arteriovenous malformation.

We do not have facilities for selective embolization and the plan was to ligate the left external carotid artery (ECA), to reduce the vascularity of the lesion, with excision of the AVM within 48 hours of the ligation. The ligation of the left ECA was done with complete resolution of the pulsations. Excision of the AVM could not be done within the proposed time due to lack of funds. She did not have health insurance and we had been assured by her parents that funds for the two stages of the surgery were available. Consequently, she had to be discharged to the outpatients' clinic with the plan to readmit for excision as soon as funds were available for surgery. Development of collaterals to the lesion was noted 4 weeks after the left ECA ligation by the reappearance of pulsation of the pinna. Total 
excision of the AVM was attempted 6 months after the initial surgery but was abandoned largely due to involvement of the whole pinna save the lobule (consent was not taken for total auriculectomy) and significant primary haemorrhage exceeding the available blood and blood products at that time (Figure 4).

The plan was to reschedule surgery with consent for possible left total auriculectomy, staged auricular reconstruction in conjuction with the Plastic and Reconstructive surgery team and provision of more units of blood. Spontaneous bleeding began again 2 weeks post operatively albeit not life threatening. She subsequently had partial auriculectomy with complete excision of the AVM and postauricular scalp rotation flap cover of the defect with the preserved auricular cartilage buried within the defect for a second stage auricular reconstruction (Figure 5). Primary haemorrhage was also significant, (approximately 1.2 litres) and she had 3 units of blood transfused intraoperatively.

Histology of the excised specimen was arteriovenous malformation (Figure 6). She made a full recovery with noclinical evidence of recurrence of the AVM one year post-operative follow up. At present however, there are no funds for the auricular reconstruction.
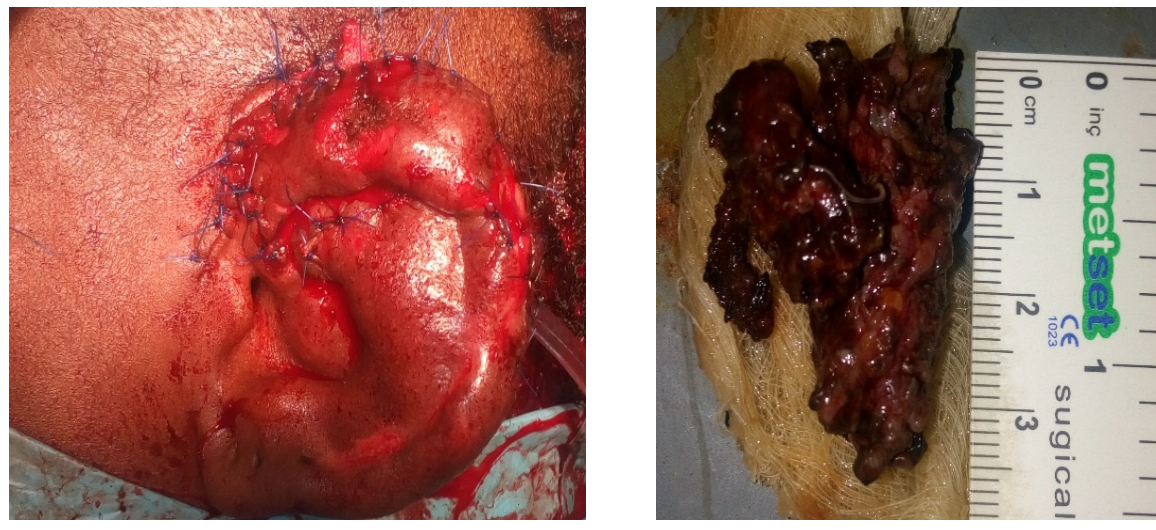

Figure 4. Left Arteriovenous malformation excision.
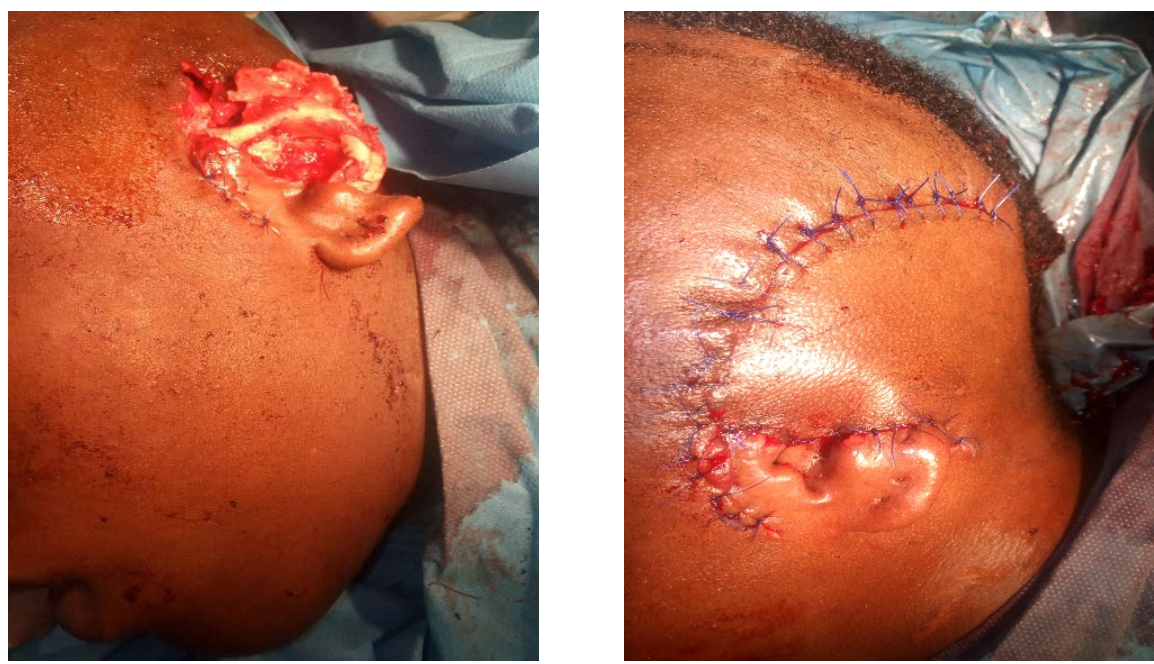

Figure 5. Intraoperative image of AVM excision with postauricular scalp advancement flap. 

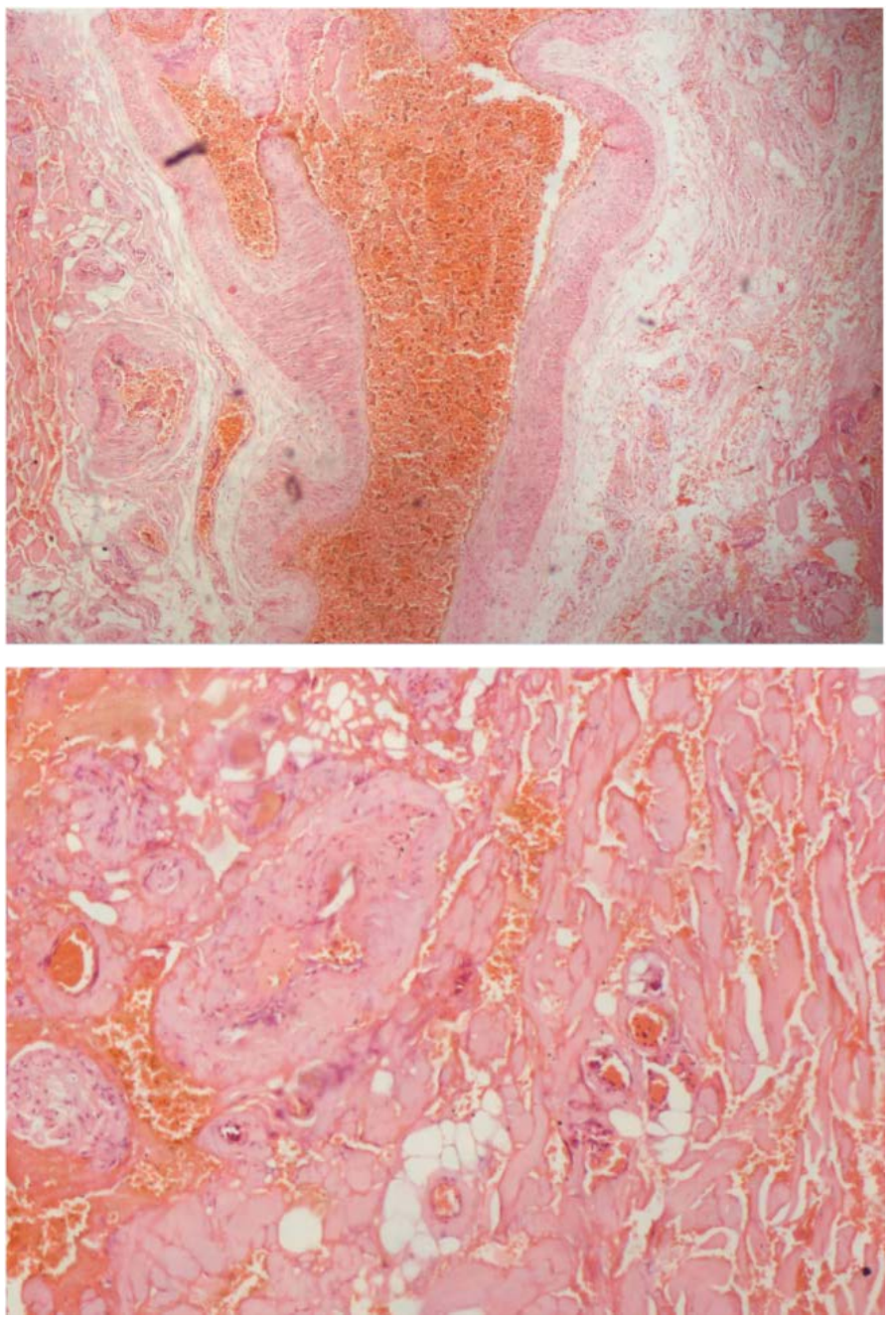

Figure 6. Abnormal thick walled tortuous vessels with intraluminal haemorrhage in keeping with AVM.

\section{Discussion}

Arteriovenous malformations are of two types, high-flow AVM and low-flow AVM [7]. The true incidence of extracranial AVM has not been reported due to its rarity, however, Kohout et al. reviewed 84 patients with AVM of the head and neck region seen over a period of 20 years and found out that $16 \%$ of the patients had AVM of the ear second only to the cheek (31\%) [4]. It has been classified into four stages according to Schobinger. Stage I is described as the quiescence stage, stage II is expansion, stage III is the destruction stage while stage IV is called the decompensation stage where the patients develop congestive cardiac failure [4]. The index patient presented with a stage III disease. The exact cause of AVM is unknown, however, it has been postulated that failure of regression of arteriovenous channels in the primitive retiform plexus during embryogenesis is responsible [8]. Trauma, infection, hormonal influences and ischaemia have been noted to promote rapid growth of AVM. Hormones were probably responsible in this index patient who had rapid increase of the lesion during adoles- 
cence. Pulsations, diffuse swelling of the pinna, ulceration and bleeding are classical findings in patients with stage III AVM of the pinna. This makes clinical diagnosis quite straightforward, although this is not always the case as reports of initial misdiagnosis have been noted. This was the case in our patient who was initially diagnosed and managed for Auricular Haemangioma at the source of referral [3]. Diagnostic and interventional radiological procedures make management of AVM less difficult. Magnetic Resonance Imaging and Angiography help define the extent of the lesion and outlines the feeding vessels respectively. Superselective embolization is an interventional radiological procedure which helps to reduce blood supply to the AVM. This is to be followed by complete excision 24 to 72 hours after embolization [6] [9]. This is not available in our center and as a result we opted to ligate the external carotid artery but due to financial constraints, the patient could not afford excision of the AVM within $48 \mathrm{hrs}$ of ligation of the ECA for excision of the AVM. Health insurance is still quite rudimentary in our society with only about $3 \%$ of the total population being on some form of health insurance scheme [10]. This has led to patients paying for their own treatment and majority cannot afford to. This was responsible for the delay in surgery.

Ligation of external carotid artery in the treatment of AVM has been reported in literature. This however is discouraged as ischaemia has been shown to increase the growth of the lesion by opening up several collateral channels [11] [12]. This could explain why the second operation was abandoned due to excessive haemorrhage.

Treatment options for AVM of the pinna depend on the Schobinger stage at which the patient at presentation. Watchful waiting has been advocated for lesions at stages I and II. Stage III lesions require surgical intervention and adequate preparations must be made with respect to availability of blood and blood products most especially in the absence of preoperative embolization techniques. [2] Patients should also be counselled and consent taken for auricular resection. [2] This is because incomplete excision of the lesion will result in recurrence with an aggressive behavior. Lifetime follow-up of these patients is recommended because of the high recurrence rate [4]. The patient should also be made aware of the possibility of recurrence as this may encourage them to adhere to follow-up guidelines.

\section{Conclusion}

Arteriovenous malformation of the pinna is a rare disorder of vascular development. History and physical examination can help in making a clinical diagnosis, however, diagnostic and interventional radiological procedures are important in knowing the extent of the lesion and planning surgical intervention.

\section{Conflicts of Interest}

The authors declare no conflicts of interest regarding the publication of this paper. 


\section{References}

[1] Meher, R., Varshney, S. and Pant, H.C. (2008) Arteriovenous Malformation Related to the Pinna. Hong Kong Medical Journal, 14, 157-159.

[2] Wu, J.K., Bisdorff, A., Gelbert, F., Enjolras, O., Burrows, P.E. and Mulliken, J.B. (2005) Auricular Arteriovenous Malformation: Evaluation, Management, and Outcome. Plastic and Reconstructive Surgery, 115, 985-995. https://doi.org/10.1097/01.PRS.0000154207.87313.DE

[3] Kim, S.H., Han, S.H., Song, Y., Park, C.S. and Song, J.-J. (2016) Arteriovenous Malformation of the External Ear: A Clinical Assessment with a Scoping Review of the Literature. Brazilian Journal of Otorhinolaryngology, 83, 683-690.

[4] Kohout, M.P., Hansen, M., Pribaz, J.J. and Mulliken, J.B. (1998) Arteriovenous Malformations of the Head and Neck: Natural History and Management. Plastic and Reconstructive Surgery, 102, 643-654. https://doi.org/10.1097/00006534-199809010-00006

[5] Mukherjee, D.K. and Okeowo, P. (1976) Arterio-Venous Fistula of the Ear. Journal of Laryngology and Otology, 92, 169-176. https://doi.org/10.1017/S0022215100085194

[6] Gupta, A., Gupta, S., Kumar, A., Bhattacharaya, S. and Jha, M. (2018) High-Flow Vascular Malformation of Ear: A Case Report. World Journal of Plastic Surgery, 7, 256-260.

[7] Jackson, I.T., Carreño, R., Potparic, Z. and Hussain, K. (1993) Hemangiomas, Vascular Malformations, and Lymphovenous Malformations, Classification and Methods of Treatment. Plastic and Reconstructive Surgery, 91, 1216-1230. https://doi.org/10.1097/00006534-199306000-00006

[8] Whitty, L.A., Murray, J.D., Null, W.E., Elwood, E.T. and Jones, G.E. (2009) An Arteriovenous Malformation of the External Ear in the Pediatric Population: A Case Report and Review of the Literature. Canadian Journal of Plastic Surgery, 17, e45-e47. https://doi.org/10.4172/plastic-surgery.1000617

[9] Tuan, H.P., Brian, J.F.W. and Allison, G. (2001) A Large Arteriovenous Malformation of the External Ear in an Adult: Report of a Case and Approach to Management. Laryngoscope, 8, 1390-1394. https://doi.org/10.1097/00005537-200108000-00014

[10] National Population Commission of Nigeria and ICF International (2014) Nigeria Demographic and Health Survey 2013. Rockville, MD.

[11] Gupta, R. and Agrawal, A. (2015) Arteriovenous Malformation of External Ear and Temporal Region: A Case Report. International Journal of Research in Medical Sciences, 3, 3427-3429. https://doi.org/10.18203/2320-6012.ijrms20151205

[12] Yoshimasa, K. and Yuji, K. (1995) Arteriovenous Malformation with Auricular Hypertrophy. ORL, 173, 224-227. https://doi.org/10.1159/000276745 